\title{
Technology adoption in small and medium-sized logistics providers
}

\section{Structured Abstract}

Purpose - The main aim of the research is to shed light on the role of information and communication technology (ICT) in the logistics innovation process of small and mediumsized third party logistics providers (3PLs).

Design/methodology/approach - A triangulated research strategy was designed using a combination of quantitative and qualitative methods. The former involved the use of a questionnaire survey of small and medium-sized Italian 3PLs with 153 usable responses received. The latter comprised a series of focus groups and the use of seven case studies.

Findings - There is a relatively low level of ICT expenditure with few companies adopting formal technology investment strategies. The findings highlight the strategic importance of supply chain integration for 3PLs with companies that have embarked on an expansion of their service portfolios showing a higher level of both ICT usage and information integration. Lack of technology skills in the workforce is a major constraint on ICT adoption. Given the proliferation of logistics-related ICT tools and applications in recent years it has been difficult for small and medium-sized 3PLs to select an appropriate system.

Research limitations/implications - The paper provides practical guidelines to researchers in the effective use of mixed-methods research based on the concept of methodological triangulation. In particular, it shows how questionnaire surveys, focus groups and case study analysis can be used in combination to provide insights into multi-faceted supply chain phenomena. It also identifies several potentially fruitful avenues for future research in this specific field.

Practical implications - The authors' findings provide useful guidance for practitioners on the effective adoption of ICT as part of the logistics innovation process.

Originality/value - There is currently a paucity of research into the drivers and inhibitors of ICT in the innovation processes of small and medium-sized 3PLs. This paper fills this gap by exploring the issue using a range of complementary research approaches. 
Keywords: Information and communication technology (ICT) adoption, small and mediumsized third party logistics providers (3PLs), logistics service market, innovation diffusion, Italy.

\section{Background}

For companies competing in highly dynamic markets, the search for new sources of competitive advantage is essential. Rapid changes in technological development are forcing businesses to look continuously for innovative strategies to improve their competitiveness. In many cases, this has revolutionised the way companies operate (Tidd et al., 2001). Technology has traditionally been viewed as the key to productivity in manufacturing industries. However, in recent decades, technology has assumed greater importance in the services sector facilitating growth by offering service firms important competitive leverage (Metcalfe and Miles, 2000). Technological innovation in services is often based on the adoption of information and communication technology (ICT) and is strongly associated with higher levels of productivity in firms (Cainelli et al., 2004).

Since the 1990s, ICT has had a profound impact on companies and business environments leading to the formation of the "network economy" (Kelly, 1998). It is enhancing the efficiency of firms' operations, accelerating the innovation process and generating added value for businesses (Porter and Millar, 1985). This is particularly evident in the logistics and supply chain management (SCM) context where ICT impacts both at the strategic and operational levels. It has transformed companies' internal logistics operations as well as their external relationships with suppliers, intermediaries, 3PLs, and customers. In essence, supply chain management (SCM) integrates supply and demand management within and across companies (CSCMP, 2011) and ICT helps it to fulfil this role. In recent years, there has been a growing shift from traditional supply chain configurations, often characterised by fragmentation, to more coordinated and integrated approaches (Esposito and Passaro, 2009). This emphasis on integration puts information management at the heart of contemporary approaches to SCM (Harrison and van Hoek, 2005; Fabbe-Costes and Jahre, 2007; Stock and Boyer, 2009). The globalisation of supply chain architectures requires that information is shared and managed internationally (Barbosa and Musetti, 2010). A common view is that ICT has a profound impact on the management of supply chains as new technologies greatly facilitate the flow of information, as well as extending control over remote operations and 
across organisational boundaries (Schary and Skjøtt-Larsen, 2001). The most important contributions of ICT in supply chains are to create end-to-end visibility, reduce cycle time and inventories, minimise the 'so-called' bullwhip effect, and improve the overall effectiveness of distribution channels (Zhang et al., 2011; Vanpouckle et al., 2009).

A major trend in the management of supply chains since the 1990s has involved the outsourcing of logistical activities to 3PLs (McKinnon, 1999; Capgemini / Penn State, 2013). 3PL companies have been transforming the scope and characteristics of their service offerings in order to improve customer service levels (Wallenburg and Lukassen, 2011). For many 3PL companies this evolution has involved the diversification of logistics services and the emergence of new forms of value creation for customers (Berglund, 2000). As a result, 3PLs play a more important role than in the past in coordinating and accelerating physical and information flows along multiple levels of the supply chain (Jayaram and Tan, 2010). This has given 3PLs a new potential role in customising supply chains as they assume responsibility for a growing number of activities beyond transportation and warehousing. As supply chain processes and planning increasingly require real-time data availability and exchange, 3PLs must have the capability to manage information flows along the entire supply chain. This has forced them to look for accurate, real-time information on the status of the entire shipment process (Inkinen et al., 2009). 3PLs have been gradually shifting from an asset-based offering to a more process-oriented approach based on knowledge and information management (Regan, and Song, 2001). Information technology capabilities are both a critical variable for logistics service differentiation (Sauvage, 2003) and a significant tool to cut costs and provide more customised services to clients (van Hoek, 2002). Annual surveys by Capgemini / Penn State University (2013) have, nevertheless, observed a "longstanding gap between the importance shippers assign to 3PLs' IT capabilities and their satisfaction with 3PLs' current IT capabilities" (p.4). This 'IT gap' appears to have been narrowing in recent years, though in the latest survey only 53\% shippers claimed to be satisfied with the level of IT support they received.

The logistics service industry is also characterised by a huge digital divide between large and small and medium-sized 3PL companies ${ }^{1}$ (e-Business Watch, 2008). While large 3PLs gained

\footnotetext{
${ }^{1}$ In this paper, the European Union definition of small and medium sized enterprises has been adopted. According to this definition, firms with less than 10 employees (and a turnover $\leq € 2$ million) are considered 'micro', firms whose employees range from 10 to 50 (and a turnover $\leq € 10$ million) are 'small', while firms
} 
substantial benefits from ICT implementation (van Hoek, 2002; Larson and Gammelgaard, 2001; van Hoek, 2000), the impact and role of ICT on the innovation processes of small and medium-sized 3PLs is unclear and under-researched (Gunasekaran and Ngai, 2003). As the importance attached to ICT in the management of logistics services had grown, so too has the interest of scholars in this topic. Their research has focused on the impact of ICT on the competitive advantage of logistics companies (Lai et al., 2006), overall company performance (Lai et al., 2007), and financial performance (Wang et al., 2008). The factors affecting the adoption of technology innovation in 3PLs (Lin, 2008; Lin, 2007; Lin, and Jung 2006), and specific applications such as RFID (Lin and Ho, 2009) have also been investigated. Nevertheless, none of the above studies have focused exclusively on small and medium-sized logistics service providers. In the extant literature, only two papers have been found which present empirical evidence on ICT usage in small and medium sized logistics companies.

The study carried out by Pokharel (2005) analyses perceptions of ICT by small and large 3PLs operating in Singapore. Out of 45 transportation and warehousing companies surveyed, 28 (19 transport companies and 9 warehousing companies) were small firms ${ }^{2}$. His analysis shows that large companies have more fully implemented ICT and show a more positive attitude towards it. Smaller companies, in general, serve relatively few customers in smaller market areas and hence perceive a lower need to invest in ICT. The author also noted that large companies are more strongly motivated to adopt ICT than smaller firms and perceive the barriers to adoption differently. Small transport companies perceive the lack of management support and in-house ICT capability as a more serious constraint than their larger counterparts, which tend to be more concerned about the adequacy of ICT resources inside and outside the business. Pokharel focused on transportation and warehousing as they account for a large proportion of the total cost of providing logistics services. $\mathrm{He}$ recommended the inclusion of a larger set of small 3PL types in future research to get a more comprehensive picture of ICT adoption and perception.

The main focus of the study conducted by Kilpala, et al. (2005) was on ICT usage by small 3PLs in the Barents region. Their results are based on a questionnaire survey involving 168

employing less than 250 people (and a turnover $\leq € 50$ million) are considered 'medium'. For further details, see European Commission (2005).

${ }^{2}$ These companies declared less than 10 million S\$ (about 4.9 million Euro) in total revenues. A similar proportion between small and large companies has been obtained in the sample investigated by Piplani, et al. (2004). The study explored the perspective on the use of ICT by 61 3PLs based in Singapore. Out of 61 companies, 40 companies declared less than S\$10 million (about 4.9 million Euro) in the total turnover. 
3PLs in Finland, Norway and Sweden, most of which are classified as micro and small companies. The survey results for 3PLs in Finland and Sweden show similarities in most aspects regarding overall development, cooperation practices and ICT implementation status. The 3PLs in the Norway sample had implemented ICT to a significantly greater extent. The results indicate that the majority of the 3PLs in the three countries were familiar with computer technology and had some ICT tools available (e.g. EDI and GPS). The study also explored motivators and barriers to ICT adoption. The improvement of control and planning was found to be the most important motivator, while the most important barriers were the low level of compatibility with current systems, lack of adequate employee training and lack of system flexibility.

While the Pokharel (2005) and Kilpala et al. (2005) studies provide valuable empirical insights into ICT adoption by 3PLs, they show some limitations. For example, the study by Pokharel (2005) adopts a classification based only on two types of logistics companies (transportation and warehousing providers), and did not include companies providing more complex logistics services in the survey. Kilpala et al. (2005) did not use any classification of the 3PL companies investigated. Both studies also rely solely on questionnaire surveys, like much of the other research on the logistics services market. As indicated in 3PL literature reviews (Maloni and Carter, 2006; Selviaridis and Spring, 2007) there has been limited use of case studies and other sources of qualitative information in 3PL research. Little use has been made of multiple methods combining quantitative and qualitative evidence.

In order to acquire a deeper understanding and in-depth knowledge of ICT uptake by small and medium-sized logistics providers, the current study used a triangulated research design, supplementing the self-completion questionnaires with interviews and focus group discussions. The focus of this study on SMEs in the logistics services market is based on a recognition that the vast majority of transport and logistics companies in the European Union are small (Eurostat, 2009). The Italian logistics service market is particularly fragmented, with a large proportion of small and medium-sized transport and logistics providers (Marchet et al., 2009). This makes it a good context for the current research.

Section 2 explains and justifies the development of the research questions and the application of the triangulated methodology. Sections 3 and 4 provide respectively an overview of the main findings from the questionnaire survey and case study phases of the empirical work. 
Section 5 integrates the findings from these phases to answer the research questions. Section 6 discusses the impications and limitations of the authors' work and identifies some potentially fruitful directions for future research.

\section{Research design and methodology}

This section presents the methodology used in this research. It is organised into four subsections:

- the research context in which the survey has been conducted

- the definition and taxonomy of 3PLs

- the main aim of the study, its research questions and overall methodological approach

- the hypothesis development process and the contingency model used to study the relationships between key variables.

\subsection{The research context: the Italian logistics service market}

The Italian logistics service market is one of the largest in Europe (after Germany, UK, France and Benelux). It is highly fragmented and therefore intensely competitive, with estimates of the number of firms in the sector ranging from 140,500 (Confetra ${ }^{3}$ ) to 205,000 (Unioncamere ${ }^{4}$ ). Of these, the great majority are "micro" road freight transport companies. This market fragmentation has placed strong pressures on 3PLs to cut rates and improve service quality.

Several large foreign logistics groups have entered the Italian market in recent years. A recent wave of mergers, acquisitions and strategic alliances has also significantly increased the degree of concentration in the sector. The market has also been subject to significant cost pressures, mainly from rising oil prices and decreasing traffic volumes during the recession (AT Kearney, 2010). This has been squeezing already low margins in the Italian trucking industry and intensifying efforts to improve operational efficiency. Central to this strategy has been the use of ICT systems (AT Kearney, 2010). Investment in ICT by Italian 3PLs appears, nevertheless, to have been relatively low by international standards (Politecnico di Milano, 2007, Marchet et al., 2009). It is worth keeping in mind, however, that the transport and logistics service industry in many countries is conservative by nature and traditionally slow to innovate (McKinnon, 2009; European Commission, 2012).

\footnotetext{
${ }^{3}$ Confederazione Nazionale del Trasporto (Confetra) is the largest Italian transport and logistics association.

${ }^{4}$ Unione delle Camere di Commercio (Unioncamere) is the Italian federation of chambers of commerce.
} 


\subsection{Definition and taxonomy of $3 P L s$}

Small and medium-sized 3PL companies must be defined to identify the targeted population. The definition is based on the following three inputs: i) existing 3PL definitions from the literature; ii) structure and evolution of the Italian 3PL industry; and iii) specific issues associated with innovation and ICT. Based on the above three inputs, the following definition of third-party logistics was adapted from Berglund et al. (1999, p. 59): “Third-party logistics are activities carried out by a logistics service provider on behalf of a shipper and consisting of at least transportation. In addition, other activities can be integrated into the service offering, for example: warehousing and inventory management, information-related activities, such as tracking and tracing, and value added supply chain activities, such as secondary assembly and installation of products". This definition is consistent with the characteristics of the Italian and European logistics service industry and is, therefore, usable in the specific context of this research. The vast majority of firms in the Italian transport and logistics sector are small and medium-sized companies providing a very limited range of purely transport services, but can be classified as 3PLs using this definition. For the purposes of this study, however, the definition of 3PL given above has been narrowed to exclude companies owning less than five vehicles. This was guided by the work of McClelland and McKinnon (2004) in the UK, which indicated that such small road haulage companies often found it difficult to operate telematic equipment profitably. This finding is consistent with the work of CSST and Cranfield University (2002), Kilpala et al. (2005) and Davies et al. (2007) For example, the study by Davies et al. (2007) of ICT usage by general road haulage firms concluded that for such smaller road haulage operators "ICT adoption is least well developed and reliance on more traditional means of operating are more prevalent" (p. 23).

It is reasonable to expect that new technologies could have a different impact on different types of company. For this reason, based on the definition given above, small and mediumsized 3PLs were classified into three categories:

- Full Haulage Providers: those companies for which transport activities represent $100 \%$ of turnover;

- Basic Logistics Providers: those companies for which transport and warehousing together comprise over $50 \%$ of turnover; and,

- Advanced Logistics Providers: those companies for which transport and warehousing together comprise less than $50 \%$ of turnover (e.g. where more than $50 \%$ of the total turnover is generated by value added logistics and SCM services). 


\subsection{Aim, research questions and overall methodology}

The main aim of the research was to shed light on the role of ICT in the logistics innovation process of small and medium-sized 3PLs. The development of the authors' two research questions has been informed by the literature review described in section 1 .

First, the extant literature shows that the extent and nature of ICT adoption in small 3PLs is not well understood as a result of the relatively small number of studies that have been carried out to date (Gunasekaran and Ngai, 2003). There have been few empirical investigations aimed at analysing and explaining the gap in ICT adoption by small logistics providers (Kilpala et al., 2005; Pokharel, 2005). This is surprising given that the majority of logistics service providers are small and medium sized companies in most EU countries (Eurostat, 2009). Second, the literature survey demonstrated that effective information management and the development of appropriate ICT capability are critical drivers of change, given the role of value-added services in strategic differentiating logistics service businesses (Sauvage, 2003; van Hoek, 2002). The provision of such value-added logistics services has long been considered an important feature of 3PL firms (see, for example, Bowersox and Closs, 1996). Third, the literature highlighted the potential benefits of ICT in improving management practices of SMEs generally (see, for example, Love and Irani, 2004) and in improving the operational efficiency of small 3PLs specifically (Gunasekaran and Ngai, 2003).

These arguments combined to inform the development of the authors' first research question: RQ1 - What ICT practices are currently used in the provision of value added services by small and medium-sized 3PLs?

The literature on ICT in SMEs has often concentrated on identifying the main barriers and motivators to technology adoption (see, for example: Martin and Matlay, 2001; Mehrtens et al., 2001; Boyes and Irani, 2004; Love and Irani, 2004). In the logistics service literature, the importance of barriers and motivators to ICT usage has not been widely investigated with few studies in this sector (see, for example: Piplani, et al., 2004; Pokharel, 2005; Kilpala et al., 2005). As a result, the drivers, enablers and inhibitors of ICT adoption in small logistics companies remain unclear. This has informed the development of the authors' second research question:

RQ 2 - What are the major drivers, enablers and inhibitors of ICT usage in small and medium-sized 3PLs?

To answer these research questions a triangulated research strategy was designed using a combination of quantitative and qualitative methods. Triangulation is the use of multiple data 
sources to corroborate evidence based on the rationale that the particular limitations of a given method will be counter-balanced by the strengths of another (Jick, 1979). The choice of a multiple research approach provides a clearer and more detailed picture of the phenomenon investigated and is particularly appropriate in the field of logistics, where empirical research has been employing a wider range of data collection methods (New and Payne, 1995). The research also responded to the observation of Selviaridis and Spring, (2007) that there is an increasing need to develop research in the logistics service industry that combines quantitative and qualitative findings within a triangulation framework.

In this paper findings from a questionnaire survey have been combined with evidence derived using case study analysis and focus group discussions. The logic behind the use of this approach is that the research questions formulated above require multiple sources of evidence to be fully explored. This application of triangulation combined quantitative and qualitative research methods. Data was collected by means of focus groups, postal questionnaires and a series of case studies as indicated in Figure 1. By employing several data sources and measures it was possible to provide cross-checks on data accuracy and to enrich the conclusions as suggested by Harrigan (1983).

\section{Place Figure 1 around here}

The empirical research activities started with the establishment of two focus groups to refine basic survey objectives and the draft version of the questionnaire. The two meetings also allowed industry associations and other key stakeholders to get involved in the research process. Afterwards, the questionnaire survey was distributed to a sample of small and medium-sized Italian 3PLs. Once the survey results were obtained, a further focus group was held involving a panel of experts selected from the participants in the previous meetings. The main objectives of the meeting were to discuss and validate survey results, and obtain some guidance for the case study analysis. The final step involved the primarily qualitative stage of the research process - i.e. a case study analysis carried out in a set of 3PL companies that had participated in the questionnaire survey.

The use of a questionnaire survey in this study can be justified on several grounds. Firstly, survey research is well suited for answering questions concerning "what is happening?" (Pinsonneault and Kraemer, 1993). A survey is efficient in terms of speed and cost in generating large amounts of data that can be subjected to statistical analysis (Snow and 
Thomas, 1994). Finally, it also allows for large numbers of respondents to be surveyed even if they are widely distributed geographically (Mangione, 1998).

Despite the advantages associated with the use of focus groups in management research (see for example Morgan, 1998; Blackburn and Stokes, 2000; Bryman and Bell, 2003), their overall level of acceptance in logistics and SCM research remains low (Naslund, 2002; Craighead, et al., 2007; Rodrigues et al., 2008). This is particularly true in the case of 3PL research as argued by Maloni and Carter (2006) and Selviaridis and Spring (2007). The use of focus group discussions at an early stage of the research project was mainly motivated by the fact they can be valuable in designing good questionnaires and in testing the beliefs and opinions of key stakeholders. The focus group findings have been used to validate the authors' overall research questions and to support the development of detailed hypotheses, as well as in the analysis and validation of questionnaire findings and design of the case studies. This is in line with the approach used by Sink et al. (1996) who used focus group discussions in their investigation of buyer perceptions of 3PLs in the USA.

The use of the case study approach in this research is well suited to the exploratory and theory building nature of the study (Ellram, 1996; Meredith, 1998). Case analysis provides insights into "how" and "why" ICT is used in small and medium-sized logistics companies. In this way, information emerging from the authors' case study analysis complements the findings from the questionnaire investigation. Given the largely qualitative nature of some of the authors' research questions, case study evidence has the potential to generate deeper and richer insights into the phenomena under investigation.

\subsection{Hypothesis development and contingency model}

The research questions stated above were investigated using five key variables:

- Company profile;

- ICT profile;

- Role of ICT in service customization;

- Perception of ICT role; and

- Factors influencing ICT adoption.

The variables were selected on the basis of: i) the results of the literature review; ii) other similar surveys conducted in the small 3PL sector (Pokharel, 2005; Kilpala et al., 2005) or other 
industries (e.g. Love and Irani, 2004); iii) the outcome of the focus groups; and, iv) the experience of the researchers. For each variable considered, a set of hypotheses was formulated in line with the two overall research questions. In total, 19 hypotheses were developed, and each was tested using data collected in the questionnaire survey. In line with convention, hypothesis testing involved assessing whether a null hypothesis could be rejected. This ensured objectivity and helped to avoid bias. The null hypotheses were grouped in accordance with the identified variables as indicated in Table 1.

\section{Place Table 1 around here}

A contingency model was constructed to map the inter-relationships between the five sets of variables that were to be subject to hypothesis testing (Figure 1). The model was based on the supposition that ICT usage does not automatically lead to an improvement in the competitive capability of small and medium-sized 3PLs. Furthermore, it is likely that the introduction of new technology will have a differential impact on the three types of small and medium-sized 3PLs in the taxonomy. The arrows in Figure 2 show the nineteen relationships whose significance was statistically tested.

\section{Place Figure 2 around here}

Hence, the testing of hypotheses is based on quantitative evidence only, while the qualitative information emerging from the case study analysis has been used to provide deeper and richer insights.

\section{Questionnaire survey method and findings}

The survey methodology was organized into the following six steps:

a) Preparation of the draft questionnaire.

b) Focus group discussions with 20 key actors (ICT managers of small and medium-sized 3PLs, ICT consultants, directors of Italian logistics associations, researchers and academics) to test the suitability and comprehensibility of the questionnaire.

c) Re-focusing of survey objectives and the questionnaire. On the basis of the focus group feedback the final questionnaire contained 37 questions, divided into four sections.

d) Defining the population of businesses. The target population for this research was estimated to be approximately 21,500 companies. 
e) Construction of the sampling frame. A sample of 1,992 small and medium-sized 3PLs was randomly compiled using company information obtained from several sources, mainly the Italian logistics associations.

f) Survey implementation. The questionnaire was mailed to 1,992 companies throughout Italy. 169 were returned, 153 containing usable responses (7.7\% response rate).

These steps were conducted in sequence over a 12 month period. To detect any possible nonresponse bias, a two-step analysis was carried out. Firstly, a sub-sample of non-respondents was contacted for information about some key demographic characteristics (such as company age, company size and type of activity) to be compared with respondents. This step did not indicate any significant bias. In a subsequent step, the method adopted by Goode and Stevens (2000) was used. Accordingly, the usable responses were split into two sets, respectively of 76 and 77 responses based on the dates on which they were received. A Mann-Whitney and chi-squared analysis of three key demographic variables revealed insignificant differences between the two groups of companies. Given the importance of the authors' proposed 3PL taxonomy in the analysis, a Cronbach's alpha was calculated to test inter-item reliability. Its value was 0.91 indicating a strong inter-item reliability and, therefore, supporting the validity of the proposed classification. The data obtained from the survey was used for statistical testing of the 19 hypotheses that were analysed using a variety of statistical tests. Table 2 summarizes the result of hypothesis testing and indicates that ten of the null hypotheses yielded significant results at the $5 \%$ level, resulting in their rejection. The rest of this section will focus on the eight relationships that were found to be highly statistically significant.

\section{Place Table 2 around here}

The positive correlation between firm size and the ICT tools used (H3) is likely to reflect the relative financial strength (e.g. higher levels of turnover and investment) of larger companies, as well as their generally broader logistical service portfolio. Moving from full haulage to advanced logistics categories sharply increases the number of value added services offered (H5). This allows the authors to have some confidence in the robustness of the proposed 3PL taxonomy. The positive correlation between the number of ICT tools adopted and the number of value added services supplied (H6) indicates that ICT is a critical support tool in increasing the level of sophistication and differentiation of logistics services. There were significant differences between the three types of 3PL and the number of ICT tools they used (H10). The data showed that the average number of ICT tools adopted increases as one moves from full haulage to advanced providers, reflecting increasing capability and service diversification. 
Advanced logistics providers had a significantly higher level of ICT integration than full haulage companies (H11). The perceived need among full haulage respondents to integrate information systems with other supply chain participants is often limited to establishing a connection with larger 3PLs to whom they act as sub-contractors. In contrast, advanced logistics service providers generally manage the physical and information flows associated with the activities of their customers as confirmed by the positive correlation found between the number of ICT tools used and the level of ICT integration with supply chain partners (H9). A more detailed analysis conducted on the level of information system integration confirms that the vast majority of providers $(85.9 \%)$ have no integration with other supply chain participants. There are, nevertheless, significant variations between the three types of 3PL with the level of information system integration increasing as one moves from full haulage to advanced logistics providers. This is indicated by the positive correlation found between the number of value added services provided and the level of supply chain integration (H7). This means that companies providing more value added services generally have a higher degree of information integration with other supply chain partners.

There is a positive correlation between the 3PL category and the provision of track and trace services (H15). Across the total sample of 3PLs, however, only $38 \%$ offer tracking and tracing services. These services are provided at shipment document level (24.7\%), container level $(14.7 \%)$ and package level (12.7\%). Tracking services at pallet and inventory level (9.3\%) are very rare. Companies appear to be at an early stage in the development of this functionality.

3PL type is not positively correlated with the availability of financial resources for ICT investment aimed at customer service improvement (H16). Full haulage companies show a lower propensity to invest in ICT for improving customer service than the advanced logistics providers. In the case of full haulage firms, the service provided is purely a transport service and increasingly regarded by the customer as a commodity. In contrast, advanced logistics companies provide a range of value added services to their customers and manage a network of other logistics providers to whom transport and other traditional services are outsourced. They have, therefore, more to gain from the application of ICT.

Figure 3 summaries the results of the statistical testing in the form of a contingency model and indicates whether the hypothesized relationships were very significant (VS), significant (S) or not significant (NS). 


\section{Place Figure 3 around here}

\section{Case study methodology and findings}

As noted in section 2 (above), the collection and analysis of questionnaire data was supplemented by a series of case studies to examine the key relationships in greater depth using mainly qualitative data. A multiple case study approach was chosen to increase the opportunity for theory building. According with Yin (1994) six to ten cases should provide enough evidence to support or reject propositions, while Eisenhardt (1989) recommend four to ten. The overall process was as follows:

a) selection of a set of appropriate companies from the sample compiled for the questionnaire survey;

b) preliminary phone inquiry with the selected companies;

c) in-depth face-to-face interviews with managers in a subset of seven companies chosen on the basis of their answers during the phone inquiry.

A set of 43 companies was selected from the questionnaire survey mailing list (10 Full Haulage, 21 Basic Logistics and 12 Advanced Logistics) using two criteria: i) the company turnover by type of service provided; and ii) the number and sophistication of ICT tools adopted. In order to select case companies with sharply contrasting characteristics, each of the three groups has been divided into two subsets of companies with extremely different profiles in terms of range of service provided and technology adopted. Subsequently, phone calls were made to invite companies to participate in the survey. Seven companies agreed to participate (two Full Haulage, three Basic Logistics and two Advanced Logistics). Three companies were selected from the Basic Logistics category because this has the largest number of companies in the sampling frame. Table 3 reports a summary profile of the case companies.

In-depth interviews were conducted at each company site. Interviews of approximately 90 minutes each in duration were held with the IT manager and/or the operations manager of each company. During the meetings a data collection guide was used to ensure that the main issues were addressed as comprehensively as possible. In addition to the interviews, a variety of information sources concerning the companies was used to construct a profile that was as detailed and as accurate as possible. Information came from company reports, company webpages, logistics internet websites and illustrative materials such as brochures, newsletters and other publications. 


\section{Place Table 3 around here}

A cross-case analysis was conducted, comparing companies both within and between categories with respect to the main issues under investigation and the main findings are described below.

The technological profile of the case companies indicate that only three companies (Basic Logistics 3, Advanced Logistics 1 and Advanced Logistics 2) have an ICT department coordinated by an ICT manager. Four of the companies reported an increase in ICT expenditure motivated by the need to update hardware and software and/or to adjust technical standards to the different ICT requirements of customers. Three companies (Full Haulage 2, Basic Logistics 1 and Basic Logistics 2) used a freight e-marketplace but, overall, the level of information exchange with other supply chain participants (mainly customers and other 3PLs) was generally low.

The customisation of service was analysed with reference to the following three factors: software usage, provision of tracking and tracing (T\&T) functionality and the role of the Internet and company website usage. Most of the case companies (five out of seven) used software applications to customise their services. The two companies that did not (Full Haulage 1 and Basic Logistics 2) cited a variety of reasons including the lack of operational necessity, high cost, low flexibility and poor user-friendliness. The provision of T\&T capability was more limited in the sample, with only two companies (Basic Logistics 3 and Advanced Logistics 1) providing this functionality. The others justified their non-use mainly on the grounds that customers did not demand it and their existing ICT systems would not support it. The vast majority of companies - six out of seven - believed that the web could strengthen their competitive positions mainly by facilitating information retrieval, reducing marketing and communication costs, and integrating the systems and applications of different companies in the supply chain. The importance accorded to the Internet in managers' answers is not reflected, however, in company website usage. Using the KPMG Internet Maturity Model (see Ellinger et al., 2003), to assess the level of company website usage it emerged that no companies in the sample reached the highest stage (interactive). Most of the case companies, four out of seven, (Full Haulage 1, Full Haulage 2, Basic Logistics 2 and Advanced Logistics 2) use their websites to provide general company information rather than 
using it interactively (marketing stage). It is interesting to note that the relatively low level of usage of the company website is common across all three provider categories.

The case study investigation allows several factors promoting the diffusion of ICT to be identified. These included: the decline in the real cost of software and hardware, the increasing need for up-to-date information on market trends, changing regulations on, for example, the traceability of food products and the vehicle manufacturers embedding of more ICT in new trucks. Working against these drivers was a series of constraints on the uptake of ICT. These included the perception that ICT products and services were generally not aligned with small and medium-sized 3PL needs, the high level of fragmentation in the industry and uncertainty about future competitive scenarios.

\section{Discussion}

This section discusses key findings emerging from the present study. The first part is an integrated discussion of the findings from the survey and case study phases of the authors' research. The second part compares the findings emerging from the present study with those from the surveys carried out by Pokharel (2005) and Kilpala et al. (2005) in order to highlight points of convergence and divergence.

\subsection{Discussion of the main findings of the present study}

Firstly, the survey indicates that the overall level of ICT expenditure compared with total company expenditure is fairly low and it does not significantly vary across provider categories. Secondly - and as suggested by this relatively low level of technology investment - very few of the surveyed companies appeared to have a formal technology investment strategy. This finding was in line with the approach of the majority of the case study firms in relation to the use of: (i) software for service customisation; (ii) T\&T functionality; and, (iii) the Internet and company websites. As suggested by Haug et al. (2011), this indicates that those companies that have implemented customer-focused service innovation strategies tend to use ICT to support these strategies and to implement business process change. In this way, the findings suggest that management with a longer term strategic view of the business tend to adopt more proactive ICT solutions designed to reinforce and sustain the firm's competitive position. On the other side, less developed providers have a more limited appreciation of the role of technology in achieving their business objectives. For many of them, technology is not seen as important in the improvement of firm competitiveness. 
Thirdly, the analysis highlights the strategic importance of supply chain integration for 3PLs. This requires appropriate investment in information systems to improve the integration of logistics operations with customers and other supply chain partners. Fourthly, companies that have embarked on the expansion of their service portfolios (e.g. into value added customised logistics services) show a higher level of both ICT usage and information integration. The study found, however, that technology is, as yet, not widely used in customising service offerings, as illustrated by the basic use of the internet website by most companies. Fifthly, lack of technology skills in the workforce is a major constraint both on ICT adoption and the exploitation of ICT potential. Managers of small and medium-sized 3PLs must devote more resources to staff training when investing in new ICT systems (Vahovar and Lesjak, 2007).

\subsection{Comparative discussion of the findings of the present study and previous surveys}

In relation to the level of ICT usage, the comparison of findings among the present study and the two papers identified suggests that there is a high level of adoption of basic ICT tools in all three surveys. They also suggest that the adoption of more sophisticated ICT tools is higher in larger and more structured companies. In particular the Kilpala et al. (2005) study indicates that there is positive relationship between company size and the level of ICT usage. A similar relationship has been found in this study (see hypothesis H3). The Pokharel (2005) study indicates that the usage of more advanced technological tools tends to decrease in companies offering basic and standard services such as transportation companies. In the present study, this finding is confirmed by the positive relationship between the number of ICT tools used and 3PL categorisation (see hypothesis H10).

Comparing the status of ICT implementation in the Pokharel (2005) study and in the present investigation, two interesting elements are evident. The first is that no significant differences exist between the studies in relation to the perception of the current status of ICT application implementation. The second point relates to the fact that most interactive applications (such as CRM and ERP) are not widely implemented in both samples investigated, while software to manage basic logistics activities (e.g. transport and warehousing) shows a higher level of implementation.

Interesting differences emerged between the present study and the two other surveys in relation to ICT drivers. The companies analysed in the Pokharel (2005) and Kilpala et al. (2005) studies attributed higher importance to factors improving internal efficiency such as 
operational cost and inventory management. The findings from the present study indicate that factors improving supply chain interactivity and service customisation are considered important drivers to facilitate ICT adoption. In relation to barriers to ICT adoption, high investment costs, inadequate employee training and lack of awareness of the ICT benefits were considered the most important barriers to ICT adoption in the Kilpala et al. (2005) survey. The findings of the present study suggest similar inhibiting factors. As in the Pokharel (2005) study, the case study analysis in the present study indicates the lack of appropriate ICT products and services in the market as one of the main constraints on ICT implementation in full haulage firms.

\section{Implications, limitations and directions for further research}

The results presented in the previous section highlight some issues of particular interest to managers in small and medium-sized 3PLs, as well as to suppliers of ICT equipment and software. Firstly, the present study highlights the strategic importance of supply chain integration for 3PLs through the use of ICT - an issue that was not investigated in the two previous studies. Findings indicate that companies that have embarked on the expansion of their service base (e.g. value added customised logistics services) show a higher level of both ICT usage (see hypothesis H10) and information integration (see hypothesis H11). The implication is that ICT innovation plays an important role in expanding the role of 3PLs in the supply chain facilitating the diversification of the service portfolio (van Hoek, 2002; Sauvage, 2003). Secondly, given the proliferation of logistics-related ICT tools and applications in recent years, it can be difficult for small and medium-sized 3PLs to select an appropriate application or software (Helo and Szekely, 2005). This suggests that managers need to improve their understanding of the role of different ICT solutions, their capabilities and constraints. Finally, ICT suppliers also have an important role in providing advice and support before and after technology procurement (Haug et al., 2011; Inkinen et al., 2009). They need to recognise the specific needs of businesses at the smaller end of the 3PL market and adapt their marketing strategies accordingly. In this regard, the proposed classification of small and medium-sized 3PLs reflects a robust segmentation of the small 3PL market (see hypothesis H5). This may help ICT vendors to design and market ICT solutions more closely aligned to the characteristics of small and medium-sized logistics businesses.

The research has been exploratory in nature and as such it has been subject to some limitations. First, although the sample size of the questionnaire survey is satisfactory, a larger 
sample size could have provided a broader assessment, deeper insights and a firmer basis for generalisation. Second, information related to ICT expenditure is also difficult to obtain. ICT costs are often reported in the company accounts as overheads or amalgamated with other items. Third, the focus of the study is exclusively on the Italian logistics service market. For this reason, the validity of evidence presented in this study is limited to the Italian logistics market situation. Although the structure of this sector is highly fragmented as in other countries, one must exercise caution in extrapolating the results geographically. Nevertheless, similarities between the results of this study and those of Pokharel (2005) in Singapore and Kilpala et al. (2005) in the Nordic countries suggest that a level of generalisation may be possible.

A number of topics may be identified that would merit further investigation. First, this study is focused on the current status of ICT adoption and it does not provide any advice on how ICT should be implemented in the 3PL sector. By using longitudinal data, future research could investigate the process of ICT adoption and trace its impact on company operations over time. In addition, longitudinal data would permit the formulation of more appropriate policy recommendations for governmental bodies in order to accelerate the rate of ICT diffusion. Second, given the importance of smaller 3PLs in the development of the logistics service industry, comparative studies between small and medium-sized logistics service companies operating in different countries/markets would be beneficial. Such studies could help managers in comparing the business practices of small and medium-sized 3PLs operating in different countries. Third, it will be important to include a customer perspective in future studies matching service user and provider perspectives. This will improve understanding of the mechanisms that allow the use of ICT to bring mutual benefits to service provider and customer. Finally, future research should concentrate on the analysis of the ICT implementation process and its wider impact on supply chain performance.

\section{References}

AT Kearney, 2010. Scenario delle logistica in Italia. Study prepared for the Confederazione Generale Italiana dei Trasporti e della Logistica (CONFETRA), Milan, Italy (in Italian). Available at: http://www.confetra.it/it/primopiano/doc_html/ASSEMBLEA\%202011/Ricerca\%20ATKearneyCSConfetra.pdf (accessed 28 November 2012).

Barbosa, D.H., Musetti, M.A., 2010. Logistics information systems adoption: a empirical investigation in Brazil. Industrial Management \& Data Systems, 110(6), 787-804.

Berglund, M., 2000. Strategic Positioning of the Emerging Third-Party Logistics Providers, Studies in Management and Economics. Doctoral Dissertation n. 45, Linkoping, Linkoping University. 
Berglund, M., van Laarhoven, P., Sharman, G., Wandel, S., 1999. Third-party logistics: is there a future? The International Journal of Logistics Management, 10(1), 59-70.

Blackburn, R., Stokes, D., 2000. Breaking down the barriers: using focus groups to research small and medium-sized enterprises, International Small Business Journal, 19(1), 44-67.

Boyes, A.J., Irani, Z., 2004. An analysis of the barriers and problems to web infrastructure development experienced by small businesses. International Journal of Information Technology and Management, 3(2/3/4), 189-207.

Bowersox, D.J., Closs, D.C., 1996. Logistical Management: The Integrated Supply Chain Process. The McGraw-Hill Companies, New York, USA.

Bryman, A., Bell, E., 2003. Business Research Methods, New York: Oxford University Press.

Capgemini / Penn State University, 2013. 2013 Third Party Logistics Study: the State of Logistics Outsourcing. University Park, PA.

Cainelli, G., Evangelista, R., Savona, M., 2004. The impact of innovation on economic performance in services, The Service Industries Journal, 24(1), 116-130.

Centro Studi sui Sistemi di Trasporto (CSST), Cranfield University, 2002. Transport and Logistics in the digital era: a survey of telematic use by European Road Freight Operators. Survey Report, Fiera di Genova, 28-29 October, Genoa, Italy.

Council of Supply Chain Management Professionals (CSCMP), 2011. retrieved September 1, 2011 from http://cscmp.org/aboutcscmp/definitions.asp

Craighead, C.W., Hanna, J.B., Gibson, B.J., Meredith, J.R., 2007. Research approaches in logistics. Trends and alternative future directions, The International Journal of Logistics Management, $18(1), 22-40$.

Davies I., Mason R., Lalwani C., 2007. Assessing the impact of ICT on UK general haulage companies. International Journal of Production Economics, 106, 12-27.

e-Business Watch, 2008. The European e-Business Report - The Impact of ICT and e-Business on Firms, Sectors and the Economy, $6^{\text {th }}$ Synthesis Report of the Sectoral e-Business Watch, DG Enterprise \& Industry, European Commission.

Eisenhardt, K.M., 1989. Building theories from case study research", Academy of Management Review, 14(4), 532-550.

Ellinger, A.E., Lynch, D.F., Andzulis, J.K., Smith, R.J., 2003. B-to-B e-Commerce: a content analytical assessment of motor carrier websites, Journal of Business Logistics, 24(1), 199-220.

Ellram, L.M., 1996. The use of case study method in logistics research, Journal of Business Logistics, 17(2), 93-138.

Esposito, E., Passaro, R., 2009. The evolution of supply chain relationships: an interpretative framework based on the Italian inter-industry experience. Journal of Purchasing and Supply Management, 15 (2), 114-126.

European Commission, 2005. The New SME Definition. User Guide and Model Declaration. DG Enterprise \& Industry, European Commission, Bruxelles.

Eurostat, 2009. Panorama of Transport. 1990-2006 (sixth edition). Luxembourg, Office for Official Publications of the European Communities.

European Commission, 2012. Report of the High Level Group on the Development of the EU Road Haulage Market. Brussels.

Fabbe-Costes, N., Jahre, M., 2007. Supply chain integration gives better performance - the emperor's new suit? International Journal of Physical Distribution \& Logistics Management, 37(10), 835855.

Goode, S., Stevens, K., 2000. An analysis of the business characteristics of adopters and non-adopters of WWW. Technology Information and Management 1(1), 129-54.

Gunasekaran, A, Ngai, E.W.T., 2003. The successful management of a small logistics company. International Journal of Physical Distribution \& Logistics Management, 33(9), 825-842.

Harrigan, K.R., 1983. Research methodologies for contingency approaches to business strategy, Academy of Management Review, 8(3), 398-405.

Harrison, A, van Hoek, R., 2005. Logistics Management and Strategy, Harlow (UK): Prentice Hall Financial Times.

Haug, A., Pedersen, S.G., Arlbjørn, J.S., 2011. IT readiness in small and medium-sized enterprises. Industrial Management \& Data Systems, 111(4), 490-508. 
Helo P., Szekely, B., 2005. Logistics information systems: an analysis of software solutions for supply chain co-ordination. Industrial Management \& Data Systems, 105(1), 5-18.

Inkinen, T., Tapaninen,U., Pulli, H., 2009. Electronic information transfer in a transport chain. Industrial Management \& Data Systems, 109(6), 809-824.

Jayaram, J, Tan, K-C, 2010. Supply chain integration with third-party logistics providers. International Journal of Production Economics, 125 (2), 46-59.

Jick, T.D., 1979. Mixing qualitative and quantitative methods: Triangulation in action. Administrative Science Quarterly, 24(4), 602-611.

Kelly, K., 1998. New Rules for the New Economy. Ten ways the Network Economy is Changing Everything. London: Fourth Estate.

Kilpala, H., Solvang, W.D., Widmark, J., Bagaeva, A., Tuohinto, P., 2005. Analysis of ICT use in the Barents region: research findings from logistics service providers and forest industry. Sustainable Transport in the Barents Region (STBR), Publications No.11.

Lai, F., Zhao, X., Wang, Q., 2006. The impact of information technology on the competitive advantage of logistics firms in China. Industrial Management \& Data Systems, 106(9), 12491271.

Lai, F., Zhao, X., Wang, Q., 2007. Taxonomy of information technology strategy and its impact on the performance of third-party logistics (3PL) in China. International Journal of Production Research, 45(10), 2195-2218.

Larson, P.D., Gammelgaard, B., 2001. Logistics in Denmark: a survey of the industry. International Journal of Logistics Research and Applications, 4 (2), 191-206.

Lin, C., Ho, Y., 2009. RFID technology adoption and supply chain performance: an empirical study in China's logistics industry. Supply Chain Management: An International Journal, 14(5), 369-378.

Lin, C.Y., Jung, C., 2006. Influencing factors on the innovation in logistics technologies for logistics service providers in Taiwan. Journal of American Academy of Business, 9(2), 257-264.

Lin, C.Y., 2007. Factors affecting innovation in logistics technologies for logistics service providers in China. Journal of Technology Management in China, 2(1), 22-37.

Lin, C.Y., 2008. Determinants of the adoption of technological innovations by logistics service providers in China", International Journal of Technology Management and Sustainable Development, 7(1), 19-38.

Love, P.E.D., Irani, Z., 2004. An exploratory study of information technology evaluation and benefits management practices of SMEs in the construction industry. Information \& Management, 42(2), 227-242.

Maloni, M.J., Carter, C.R., 2006. Opportunities for research in third-party logistics. Transportation Journal, 45(2), 23-38.

Mangione, T.W., 1998. Mail surveys. In Bickman L., Rog D.J. (eds.), Handbook of applied research methods. Thousand Oaks (CA), Sage, 399-427.

Marchet, G., Perego, A., Perotti, S. 2009. An exploratory study of ICT adoption in the Italian freight transportation industry. International Journal of Physical Distribution \& Logistics Management, 39(9), 785-812.

Martin, L.M., Matlay, H., 2001. Blanket approaches to promoting ICT in small firms: some lessons from the DTI ladder adoption model in the UK. Internet Research: Electronic Networking Applications and Policy, 11(5), 399-410.

McClelland, D., McKinnon, A.C., 2004. Use of vehicle telematics systems for the collection of key performance indicator data in road freight transport. Heriot-Watt University, Logistics Research Centre Edinburgh, UK.

McKinnon, A.C., 1999, The outsourcing of logistical activities. In Waters, D. (Ed.). Global logistics and distribution planning, London, Kogan Page, 215-34.

McKinnon, A.C., 2009. Innovation in road freight transport: achievements and opportunities. Report prepared from the International Transport Forum workshop on 'Innovation in Road Transport', Lisbon, $\quad 2^{\text {nd }} \quad$ October. Available at: http://www.internationaltransportforum.org/Proceedings/Lisbon2009/1-McKinnon.pdf (accessed 28 November 2012).

Meredith, J., 1998. Building operations management theory through case and field research. Journal of Operations Management, 16(4), 441-454. 
Mehrtens, J., Cragg, P.B., Mills, A.M., 2001. A model of internet adoption by SMEs. Information \& Management, 39(3), 165-176.

Metcalfe, J.S., Miles, I., 2000. Innovation Systems in the Service Economy. Dordrecht, Kluwer Academic Publishers.

Morgan, D.L., 1998. Planning Focus Groups. Thousand Oaks (CA), Sage.

Naslund, D., 2002. Logistics needs qualitative research - especially action research. International Journal of Physical Distribution \& Logistics Management, 32(5), 321-338.

New, S.J., Payne, P., 1995. Research framework in logistics. Three models, seven dinners and a survey. International Journal of Physical Distribution \& Logistics Management, 25(10), 60-70.

Pinsonneault, A., Kraemer, K.L., 1993. Survey research methodology in management information systems: an assessment. Journal of Management Information System, 10(2), 75-106.

Piplani R., Pokharel S., Tan A., 2004. Perspectives on the use of information technology at third party logistics service providers in Singapore. Asia Pacific Journal of Marketing and Logistics, 16(1), 27-41.

Pokharel, S., 2005. Perception on information and communication technology perspectives in logistics - A study or transportation and warehouse sectors in Singapore. The Journal of Enterprise Information Management, 18(2), 136-149.

Politecnico di Milano, 2007. Intelligent Transportation Systems per le Merci: la Prospettiva degli Utenti. Collana Quaderni AIP, Dipartimento di Ingegneria Gestionale, Politecnico di Milano, Milan, Italy (in Italian).

Porter M.E., Millar V.E., 1985. How information give you competitive advantage, Harvard Business Review, 63(4), 149-160.

Regan, A.C., Song, J., 2001. An industry in transition: third party logistics in the information age. Proceedings of the $80^{\text {th }}$ Annual Meeting of the Transportation Research Board, January, Washington.

Rodrigues, V.S., Piecyk, M., McKinnon, A., Edwards, J., Potter, A., Naim, M., 2008. Assessing the application of the focus groups methods in the logistics discipline. Proceedings of the British Academy of Management conference (BAM), $9^{\text {th }}-11^{\text {th }}$ September, Harrogate, UK.

Sauvage, T., 2003. The relationship between technology and logistics third-party providers. International Journal of Physical Distribution \& Logistics Management, 33(3), 236-253.

Schary, P.B., Skjøtt-Larsen, T., 2001. Managing the Global Supply Chain. Copenhagen: CBS Press.

Selviaridis, K., Spring, M., 2007. Third party logistic: a literature review and research agenda, The International Journal of Logistics Management, 18(1), 125-150.

Sink, H.L., Langley, Jr. C.J., Gibson, B.J., 1996. Buyer observations of the US third-party logistics market, International Journal of Physical Distribution \& Logistics Management, 26(3), 38-46.

Snow, C., Thomas, J.B., 1994. Field research methods in strategic management: contributions to theory building and testing. Journal of Management Studies, 31(4), 457-480.

Stock, J.R., Boyer, S.L., 2009. Developing a consensus definition of supply chain management: a qualitative study. International Journal of Physical Distribution \& Logistics Management, 39(8), 690-711.

Tidd, J., Bessant, J., Pavitt K., 2001. Managing Innovation - Integrating Technological, Market and Organizational Change. $2^{\text {nd }}$ edition, John Wiley \& Sons, New York.

Vahovar, V. Lesjak, D., 2007. Characteristics and impact of ICT investments: perceptions among managers. Industrial Management \& Data Systems, 107(4), 537-550.

van Hoek, R., 2000. The role of third-party logistics providers in mass customization. The International Journal of Logistics Management, 11(1), 37-46.

van Hoek, R., 2002. Using information technology to leverage transport and logistics service operations in the supply chain: an empirical assessment of the interrelation between technology and operation management. International Journal of Information Technology and Management, $1(1), 115-130$.

Vanpoucke, E., Boyer, K.K., Vereecke, A., 2009. Supply chain information flow strategies: an empirical taxonomy. International Journal of Operations \& Production Management, 29(12), 1213-1241.

Wallenburg, C M; Lukassen, P. ,2011. Proactive improvement of logistics service providers as driver of customer loyalty, European Journal of Marketing, 45(3), 438-454. 
Wang, Q., Lai, F., Zhao, X., 2008. The impact of information technology in the financial performance of third-party logistics firms in China. Supply Chain Management: An International Journal, 13(2), 138-150.

Yin, R.K., 1994. Case Study Research: Design and Methods, Newbury Park: Sage Publications.

Zhang X., van Donk D.P., van der Vaart T., 2011. Does ICT influence supply chain management and performance? A review of survey-based research. International Journal of Operations \& Production Management, 31(11), 1215-1247. 
Table 1

Hypotheses to be tested

\begin{tabular}{|c|}
\hline Variable 1 - Company profile \\
\hline H1: Firm size is not positively correlated to the geographical extent of small logistics companies \\
\hline $\mathrm{H} 2$ : Firm size is not positively correlated to the types of small 3PL \\
\hline H3: Firm size is not positively correlated to the number of ICT tools used \\
\hline $\begin{array}{l}\text { H4: Firm size is not positively correlated to the level of ICT integration with other supply chain } \\
\text { partners }\end{array}$ \\
\hline H5: The number of value added services supplied is not positively correlated to the types of small 3PL \\
\hline $\begin{array}{l}\text { H6: The number of ICT tools used is not positively correlated to the number value added services } \\
\text { supplied }\end{array}$ \\
\hline $\begin{array}{l}\text { H7: The number of value added services provided is not positively correlated to the overall level of } \\
\text { ICT integration with supply chain partner }\end{array}$ \\
\hline $\begin{array}{l}\text { H8: The types of small 3PL are not positively correlated to the geographic market scope of small } \\
\text { logistics service companies }\end{array}$ \\
\hline Variable 2 - ICT profile \\
\hline $\begin{array}{l}\text { H9: The number of ICT tools used is not positively correlated to the overall level of ICT integration } \\
\text { with supply chain partners }\end{array}$ \\
\hline H10: The types of small 3PL are not positively correlated to the number of ICT tools used \\
\hline $\begin{array}{l}\text { H11: The types of small 3PL are not positively correlated to the overall level of ICT integration in the } \\
\text { supply chain }\end{array}$ \\
\hline H12: The types of small 3PL are not positively correlated to the ICT costs \\
\hline Variable 3 - ICT role in service customization \\
\hline H13: The types of small 3PL are not positively correlated to the TMS adoption \\
\hline H14: The types of small 3PL are not positively correlated to the website adoption \\
\hline $\begin{array}{l}\text { H15: The types of small 3PL are not positively correlated to the provision of tracking and tracing } \\
\text { services }\end{array}$ \\
\hline Variable 4 - Perception of ICT role \\
\hline $\begin{array}{l}\text { H16: The types of small 3PL are not positively correlated to the financial resources availability of } \\
\text { ICT investment in customer service }\end{array}$ \\
\hline $\begin{array}{l}\text { H17: The types of small 3PL are not positively correlated to the financial resources availability of } \\
\text { ICT investment in cost reduction }\end{array}$ \\
\hline Variable 5 - Factors influencing ICT adoption \\
\hline H18: The types of small 3PL are not positively correlated to the factors stimulating ICT usage \\
\hline H19: The types of small 3PL are not positively correlated to the factors inhibiting ICT usage \\
\hline
\end{tabular}




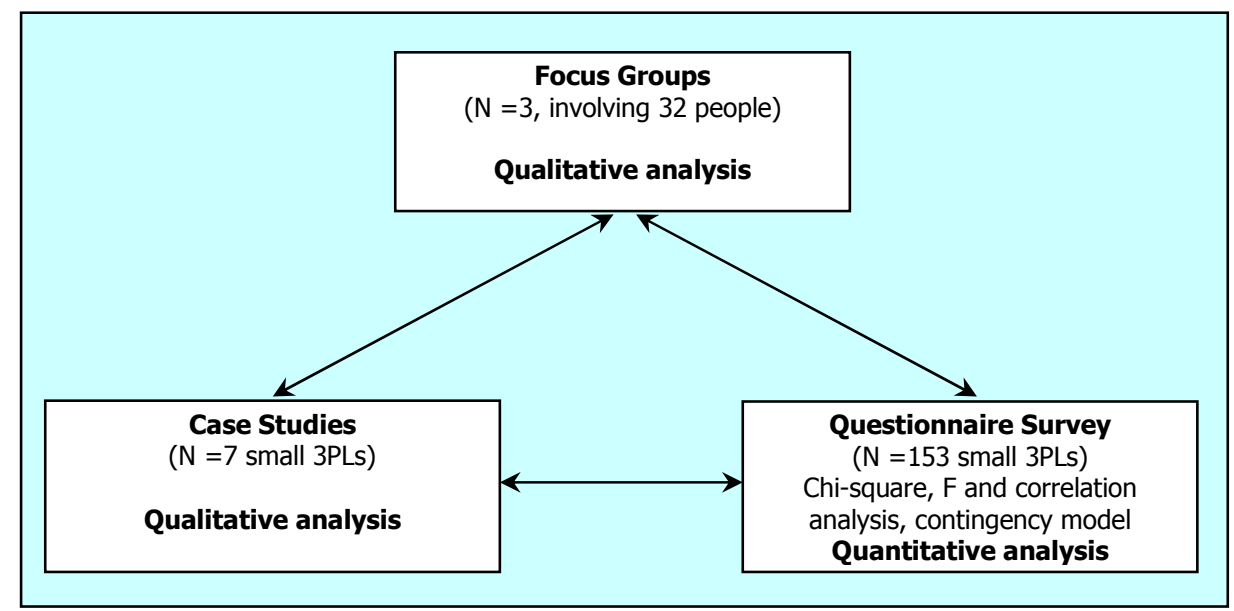

Figure 1. Research strategy: triangulation

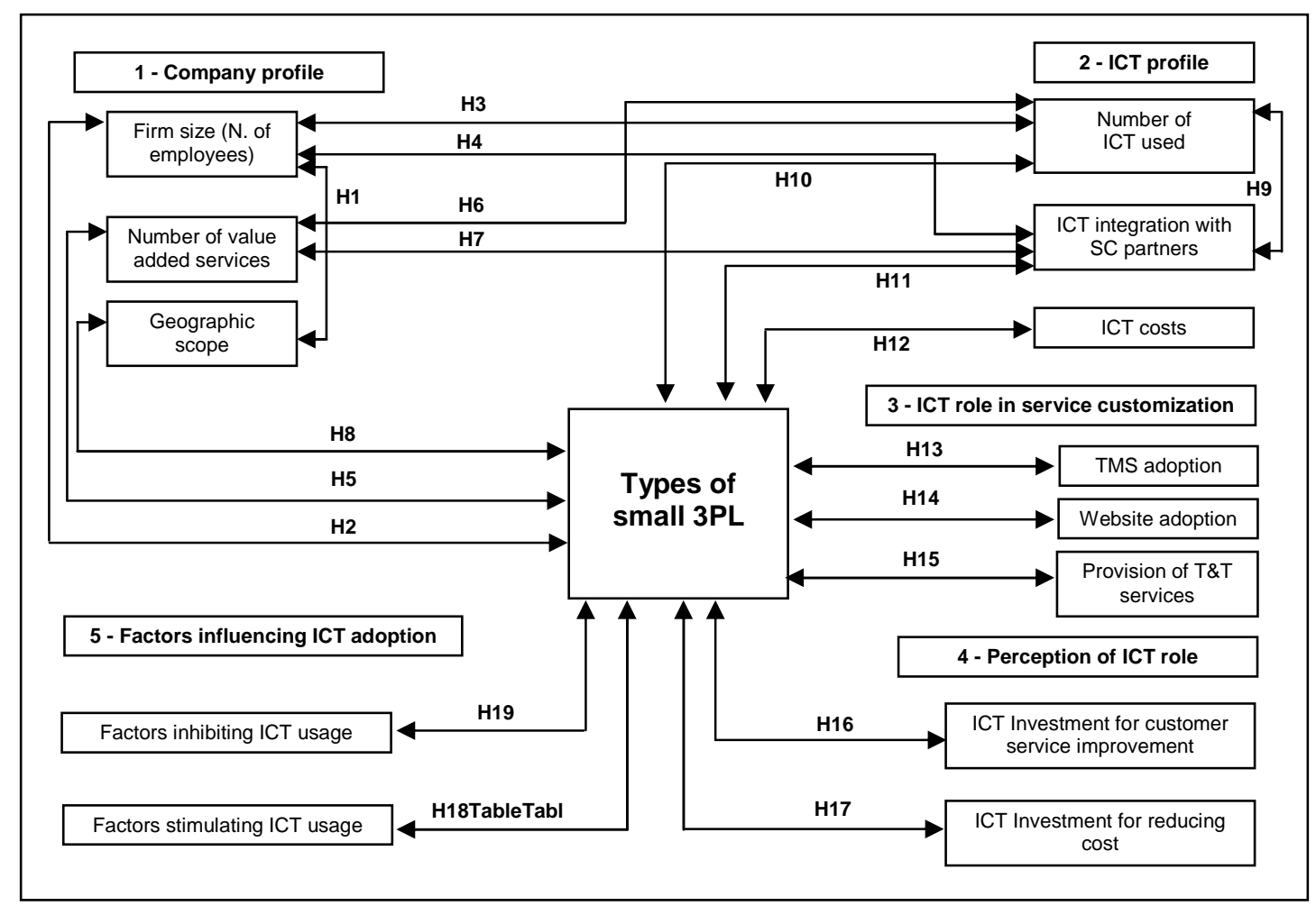

Figure 2. The contingency model 
Table 2

Summary of hypothesis test results

\begin{tabular}{|c|c|c|c|}
\hline Hypothesis $\left(\mathbf{H}_{0}\right)$ & $\begin{array}{l}\text { Very sign. } \\
\text { (VS) }\end{array}$ & $\begin{array}{l}\text { Significant } \\
(\text { S) }\end{array}$ & $\begin{array}{l}\text { Not sign. } \\
\text { (NS) }\end{array}$ \\
\hline Significance level & $\mathbf{p}<\mathbf{0 . 0 1}$ & $\mathbf{p}<\mathbf{0 . 0 5}$ & $\mathbf{p}>\mathbf{0 . 0 5}$ \\
\hline \multicolumn{4}{|l|}{1 - Company profile } \\
\hline $\begin{array}{l}\text { H1: Firm size is not positively correlated to the } \\
\text { geographical extent of small logistics companies }\end{array}$ & & & Accept $\mathrm{H}_{0}$ \\
\hline $\begin{array}{l}\text { H2: Firm size is not positively correlated to the types } \\
\text { of small 3PL }\end{array}$ & & & Accept $\mathrm{H}_{0}$ \\
\hline $\begin{array}{l}\text { H3: Firm size is not positively correlated to the } \\
\text { number of ICT tools used }\end{array}$ & Reject $\mathrm{H}_{0}$ & & \\
\hline $\begin{array}{l}\text { H4: Firm size is not positively correlated to the level } \\
\text { of ICT integration with other supply chain partners }\end{array}$ & & & Accept $\mathrm{H}_{0}$ \\
\hline $\begin{array}{l}\text { H5: The number of value added services supplied is } \\
\text { not positively correlated to the types of small 3PL }\end{array}$ & Reject $\mathrm{H}_{0}$ & & \\
\hline $\begin{array}{l}\text { H6: The number of ICT tools used is not positively } \\
\text { correlated to the number value added services } \\
\text { supplied }\end{array}$ & Reject $\mathrm{H}_{0}$ & & \\
\hline $\begin{array}{l}\text { H7: The number of value added services provided is } \\
\text { not positively correlated to the overall level of ICT } \\
\text { integration with supply chain partners }\end{array}$ & Reject $\mathrm{H}_{0}$ & & \\
\hline $\begin{array}{l}\text { H8: The types of small 3PL are not positively } \\
\text { correlated to the geographic market scope of small } \\
\text { logistics service companies }\end{array}$ & & Reject $\mathrm{H}_{0}$ & \\
\hline \multicolumn{4}{|l|}{2 - ICT profile } \\
\hline $\begin{array}{l}\text { H9: The number of ICT tools used is not positively } \\
\text { correlated to the overall level of ICT integration with } \\
\text { supply chain partners }\end{array}$ & Reject $\mathrm{H}_{0}$ & & \\
\hline $\begin{array}{l}\text { H10: The types of small 3PL are not positively } \\
\text { correlated to the number of ICT tools used }\end{array}$ & Reject $\mathrm{H}_{0}$ & & \\
\hline $\begin{array}{l}\text { H11: The types of small 3PL are not positively } \\
\text { correlated to the overall level of ICT integration in } \\
\text { the supply chain }\end{array}$ & Reject $\mathrm{H}_{0}$ & & \\
\hline $\begin{array}{l}\text { H12: The types of small 3PL are not positively } \\
\text { correlated to the ICT costs }\end{array}$ & & & Accept $\mathrm{H}_{0}$ \\
\hline \multicolumn{4}{|l|}{3 - ICT role in service customization } \\
\hline $\begin{array}{l}\text { H13: The types of small 3PL are not positively correlated } \\
\text { to the TMS adoption }\end{array}$ & & & Accept $\mathrm{H}_{0}$ \\
\hline $\begin{array}{l}\text { H14: The types of small 3PL are not positively } \\
\text { correlated to the website adoption }\end{array}$ & & & Accept $\mathrm{H}_{0}$ \\
\hline $\begin{array}{l}\text { H15: The types of small 3PL are not positively corre- } \\
\text { lated to the provision of tracking and tracing services }\end{array}$ & Reject $\mathrm{H}_{0}$ & & \\
\hline \multicolumn{4}{|l|}{4 - Perception of ICT role } \\
\hline $\begin{array}{l}\text { H16: The types of small 3PL are not positively } \\
\text { correlated to the financial resources availability of } \\
\text { ICT investment in customer service }\end{array}$ & & Reject $\mathrm{H}_{0}$ & \\
\hline
\end{tabular}




\begin{tabular}{|l|l|l|l|}
\hline $\begin{array}{l}\text { H17: The types of small 3PL are not positively } \\
\text { correlated to the financial resources availability of } \\
\text { ICT investment in cost reduction }\end{array}$ & & \multicolumn{2}{|l|}{ Accept $\mathrm{H}_{0}$} \\
\hline 5 - Factors influencing ICT adoption & & & Accept $\mathrm{H}_{0}$ \\
\hline $\begin{array}{l}\text { H18: The types of small 3PL are not positively } \\
\text { correlated to the factors stimulating ICT usage }\end{array}$ & & & Accept $\mathrm{H}_{0}$ \\
\hline $\begin{array}{l}\text { H19: The types of small 3PL are not positively } \\
\text { correlated to the factors inhibiting ICT usage }\end{array}$ & & & Acle \\
\hline
\end{tabular}

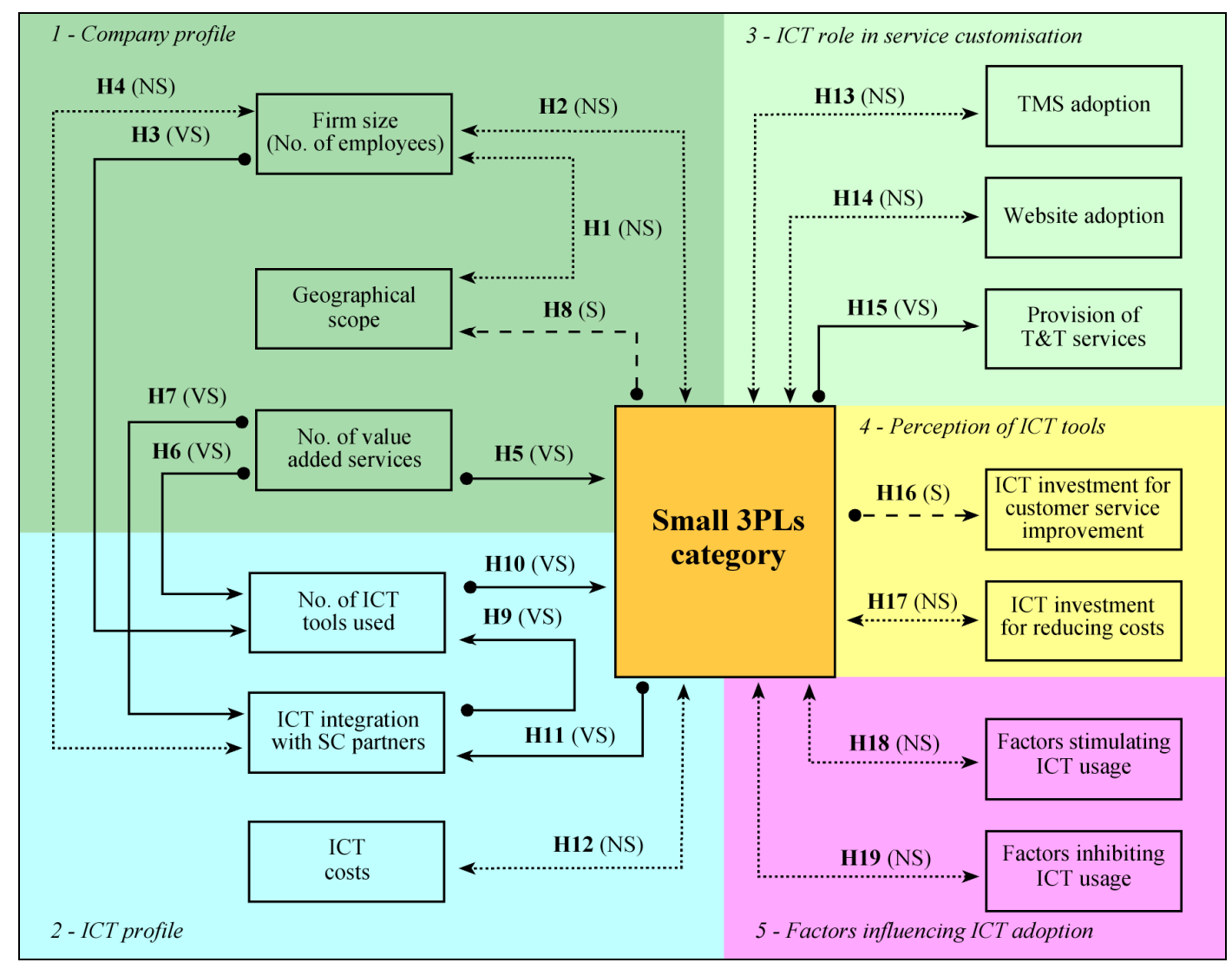

Figure 3. Summary of the statistical testing of the 19 hypotheses 
Table 3

Characteristics of the case study companies

\begin{tabular}{|l|c|c|l|c|c|}
\hline \multicolumn{1}{|c|}{$\begin{array}{c}\text { Case } \\
\text { Company }\end{array}$} & Turnover & Employees & \multicolumn{1}{|c|}{$\begin{array}{c}\text { Customer } \\
\text { industry }\end{array}$} & $\begin{array}{c}\text { No. of } \\
\text { customer }\end{array}$ & $\begin{array}{c}\text { Customer } \\
\text { concentratio } \\
\text { n }\end{array}$ \\
\hline $\begin{array}{l}\text { Full Haulage } \\
1\end{array}$ & $\leq 2$ & 11 & $\begin{array}{l}\text { Fertilisers for agriculture, } \\
\text { food \& beverage }\end{array}$ & 20 & $85 \%$ \\
\hline $\begin{array}{l}\text { Full Haulage } \\
2\end{array}$ & $\leq 10$ & $\begin{array}{c}\text { from 10 } \\
\text { to 50 }\end{array}$ & $\begin{array}{l}\text { Hazardous goods, food \& } \\
\text { beverage }\end{array}$ & 200 & $10 \%$ \\
\hline $\begin{array}{l}\text { Basic } \\
\text { Logistics 1 }\end{array}$ & $\leq 50$ & $\begin{array}{l}\text { from 51 } \\
\text { to 249 }\end{array}$ & $\begin{array}{l}\text { machinery, electronics, } \\
\text { chemical and oil, textile and } \\
\text { clothing, automotive, paper }\end{array}$ & 150 & $40 \%$ \\
\hline $\begin{array}{l}\text { Basic } \\
\text { Logistics 2 }\end{array}$ & $\leq 10$ & 7 & $\begin{array}{l}\text { Raw material for plastic } \\
\text { products }\end{array}$ & 30 & $80 \%$ \\
\hline $\begin{array}{l}\text { Basic } \\
\text { Logistics 3 }\end{array}$ & $\leq 50$ & $\begin{array}{l}\text { Biomedical, publishing, } \\
\text { textile-clothing-shoes and } \\
\text { food packaging }\end{array}$ & 200 & $90 \%$ \\
\hline $\begin{array}{l}\text { Advanced } \\
\text { Logistics 1 }\end{array}$ & $\leq 50$ & $\begin{array}{l}\text { I.T., electronics, telecom, } \\
\text { pharmaceutical, automotive, } \\
\text { banks and insurance, } \\
\text { fashion, promotional and } \\
\text { publishing }\end{array}$ & 120 & $50 \%$ \\
\hline $\begin{array}{l}\text { Advanced } \\
\text { Logistics 2 }\end{array}$ & $\leq 50$ & 200 & $\begin{array}{l}\text { Coffee, metals, cellulose, } \\
\text { rubber and perishable goods }\end{array}$ & 6,000 & $30 \%$ \\
\hline
\end{tabular}

Legend - FH: full haulage; BL: basic logistics; AL: advanced logistics; Turnover: in €million; Customer concentration: company's turnover percentage generated by the largest five customers. 